\title{
Risks, costs, and outcomes of cerebrospinal fluid leaks after pediatric skull fractures: a MarketScan analysis between 2007 and 2015
}

\author{
*Kunal Varshneya, BS, Adrian J. Rodrigues, BA, Zachary A. Medress, MD, \\ Martin N. Stienen, MD, FEBNS, Gerald A. Grant, MD, John K. Ratliff, MD, and \\ Anand Veeravagu, MD \\ Department of Neurosurgery, Stanford University School of Medicine, Stanford, California
}

\begin{abstract}
OBJECTIVE Skull fractures are common after blunt pediatric head trauma. CSF leaks are a rare but serious complication of skull fractures; however, little evidence exists on the risk of developing a CSF leak following skull fracture in the pediatric population. In this epidemiological study, the authors investigated the risk factors of CSF leaks and their impact on pediatric skull fracture outcomes.
\end{abstract}

METHODS The authors queried the MarketScan database (2007-2015), identifying pediatric patients (age $<18$ years) with a diagnosis of skull fracture and CSF leak. Skull fractures were disaggregated by location (base, vault, facial) and severity (open, closed, multiple, concomitant cerebral or vascular injury). Descriptive statistics and hypothesis testing were used to compare baseline characteristics, complications, quality metrics, and costs.

RESULTS The authors identified 13,861 pediatric patients admitted with a skull fracture, of whom $1.46 \%(n=202)$ developed a CSF leak. Among patients with a skull fracture and a CSF leak, 118 (58.4\%) presented with otorrhea and 84 $(41.6 \%)$ presented with rhinorrhea. Patients who developed CSF leaks were older (10.4 years vs 8.7 years, $p<0.0001)$ and more commonly had skull base $(n=183)$ and multiple $(n=22)$ skull fractures $(p<0.05)$. These patients also more frequently underwent a neurosurgical intervention $(24.8 \%$ vs $9.6 \%, p<0.0001)$. Compared with the non-CSF leak population, patients with a CSF leak had longer average hospitalizations (9.6 days vs 3.7 days, $p<0.0001)$ and higher rates of neurological deficits (5.0\% vs $0.7 \%, p<0.0001$; OR 7.0; 95\% Cl 3.6-13.6), meningitis (5.5\% vs 0.3\%, p< 0.0001 ; OR 22.4; 95\% Cl 11.2-44.9), nonroutine discharge (6.9\% vs 2.5\%, p < 0.0001; OR 2.9; 95\% Cl 1.7-5.0), and readmission (24.7\% vs $8.5 \%, p<0.0001$; OR 3.4; $95 \% \mathrm{Cl} 2.5-4.7)$. Total costs at 90 days for patients with a CSF leak averaged $\$ 81,206$, compared with $\$ 32,831$ for patients without a CSF leak $(p<0.0001)$.

CONCLUSIONS The authors found that CSF leaks occurred in $1.46 \%$ of pediatric patients with skull fractures and that skull fractures were associated with significantly increased rates of neurosurgical intervention and risks of meningitis, hospital readmission, and neurological deficits at 90 days. Pediatric patients with skull fractures also experienced longer average hospitalizations and greater healthcare costs at presentation and at 90 days.

https://thejns.org/doi/abs/10.3171/2019.8.FOCUS19543

KEYWORDS CSF leak; pediatric; traumatic brain injury; skull fracture

$\mathrm{S}$ KULL fractures are commonly associated with pediatric traumatic brain injury ${ }^{1,2,9}$ due to blunt trauma., ${ }^{73}$ The mechanism of trauma, extent of fracture comminution, and presence of associated intracranial injuries determine the appropriate clinical approach, risk of neurological deterioration, and overall prognosis. ${ }^{17}$ Most isolated nondepressed linear skull fractures can be managed conservatively, $3,4,6,8,9,12,17,21-23,26$ and past studies have favored discharge over 23-hour observation for these patients., ${ }^{4,621}$ However, nonlinear skull fractures, including open, depressed, and basilar fractures, are more strongly associated with intracranial pathology and morbidity 1,7 , $10,19,20,27$ and thus require careful clinical attention. CSF leaks are a known complication of these fractures ${ }^{5,10,11,16,28}$ and arise due to fistulous connection between the intradural and extracranial space. ${ }^{13} \mathrm{CSF}$ leaks often present as

ABBREVIATIONS EVD = external ventricular drain; ICD-9-CM = International Classification of Diseases, 9th Revision, Clinical Modification; LOS = length of stay. SUBMITTED July 1, 2019. ACCEPTED August 20, 2019.

INCLUDE WHEN CITING DOI: 10.3171/2019.8.FOCUS19543.

${ }^{*}$ K.V. and A.J.R. contributed equally to this work. 
clear rhinorrhea or otorrhea within the first 48 hours of injury, ${ }^{25,27-29}$ and they are estimated to occur in $2.3 \%$ of all pediatric skull fractures ${ }^{1}$ and $10 \%-30 \%$ of skull base fractures. . $^{511,13,27,28}$

While most CSF leaks resolve spontaneously, ${ }^{11,27,28}$ they substantially increase the risk of meningitis and encephalitis, ${ }^{11,13,16,20,27}$ though risk estimates vary widely among retrospective studies ${ }^{11,13,27}$ and are not as well studied in the pediatric population. Moreover, in the absence of consensus treatment guidelines, there is substantial interinstitution difference in management, in particular regarding the need for neurosurgical intervention. ${ }^{7,11,13,15}$ The literature indicates that leaks requiring surgical intervention, or persisting over time, are associated with higher rates of meningitis and mortality. ${ }^{13,16}$

Although CSF leaks are known to occur after skull fractures in a minority of cases, precise risk estimates in the pediatric population are extremely limited, ${ }^{1,16}$ and our current understanding derives from single-institution studies of skull base injuries. . $^{13,24,27,28}$ In this study, we used the MarketScan database between 2007 and 2015 to assemble a large cohort of pediatric patients with skull fractures. We examined the characteristics and clinical outcomes of pediatric skull fracture patients with and without CSF leaks, and we longitudinally assessed the healthcare costs associated with the care of these patients.

\section{Methods \\ Data Source}

This study obtained a sample of the MarketScan Commercial Claims and Encounters Database (Truven Health Analytics) from January 1, 2007, to December 31, 2015, inclusive. This database is a collection of commercial inpatient, outpatient, and pharmaceutical claims of more than 75 million employees, retirees, and dependents representing a substantial portion of the US population covered by employer-sponsored insurance. MarketScan contains 53 million inpatient records, 40 million with employersponsored insurance, 3.7 million with Medicare Part B, and 6.8 million with Medicaid. The data are updated quarterly, with all new records becoming available within 15 months of service and $91 \%$ of claims available within 5 months. Due to MarketScan's sourcing from large employers, it boasts of superior longitudinal tracking of patients' data. MarketScan data sets are publicly available to researchers for a fee per year of data. The MarketScan database contains International Classification of Diseases, 9th Revision, Clinical Modification (ICD-9-CM) and 10th Revision, Clinical Modification codes, Current Procedural Terminology codes, Diagnosis Related Group codes, and National Drug Codes.

\section{Sample}

The sample in this study consisted of 13,861 patients with a skull fracture (ICD-9-CM codes 800.xx-804.xx). Records were then queried to identify which patients developed a CSF leak by ICD-9-CM code 388.61 or 349.81 . Patients 18 years of age or older were excluded. Patients were categorized as having a skull fracture with or without CSF leak.

\section{Outcomes and Variables}

Outcomes included the development of meningitis or neurological deficits, readmission rates, inpatient mortality, nonroutine discharge (defined as any discharge not to the patient's home), and costs within 90 days from index admission. Length of stay (LOS) was also determined. Surgical treatment modalities were also compared between groups. Patient-level variables, including age at diagnosis, sex, year of admission, and quality and cost metrics, were taken directly from the claims data. Complications were assessed using ICD-9-CM codes.

\section{Statistical Analysis}

The chi-square test, t-test, rank-sum test, and logistic regression were utilized to assess significant differences in demographic data, skull fracture type, surgical treatment modalities, 90-day complications, quality outcomes, and payments among the groups. The $\mathrm{p}$ values were interpreted as significant if less than 0.05 .

\section{Patient Involvement}

As this study includes only analysis of secondary deidentified data, it was not considered human subject research and received exemption from IRB approval at our institution.

\section{Results}

In the MarketScan database we identified 13,861 pediatric patients $(<18$ years of age) with skull fractures treated between 2007 and 2015, of whom 202 (1.46\%) also had a CSF leak. Table 1 compares this group of 202 patients who had a skull fracture and a CSF leak with the rest of the group (13,659 patients), who had a skull fracture and no CSF leak. The mean age of patients with a CSF leak was 10.4 years (range $0-17$ years) compared with a mean age of 8.7 years (range $0-17$ years) in the overall cohort of patients with skull fractures $(\mathrm{p}<0.0001)$. Among the skull fracture patients with a CSF leak, $118(58.4 \%)$ presented with otorrhea and $84(41.6 \%)$ presented with rhinorrhea. Vascular injuries, including hemorrhage and arterial dissection, were observed in 123 patients (60.9\%) with CSF leaks and in 5565 of the 13,659 patients (40.7\%) in the general cohort $(\mathrm{p}<0.0001)$. Neurosurgical intervention was performed in 50 patients $(24.8 \%)$ with a CSF leak and in $1313(9.6 \%)$ of the 13,659 patients without a CSF leak (p $<0.0001)$.

First, the longitudinal impact of skull fractures on healthcare expenditure and LOS was assessed (Figs. 1 and 2). The total number of skull fracture admissions declined by more than $40 \%$ between 2007 and 2015 (Fig. 1), from roughly 70 in every 100,000 admissions to 45 . Over the same interval, the average LOS fell from 4.2 days to 3.4 days $(-19 \%)$, and the mean total cost increased from $\$ 35,661$ to $\$ 38,402$ (+7.1\%) (Fig. 2).

Skull fractures with and without CSF leaks were stratified by fracture location (Table 1), with skull base fractures occurring more frequently in the CSF leak population $(\mathrm{n}=183 ; 90.6 \%)$ than in the non-CSF leak population $(\mathrm{n}=7162 ; 52.4 \%)(\mathrm{p}<0.0001)$. Closed fractures, including depressed and growing fractures, represented the majority 
TABLE 1. Demographics and clinical characteristics

\begin{tabular}{|c|c|c|c|}
\hline \multirow[b]{2}{*}{ Variable } & \multicolumn{2}{|c|}{ Skull Fractures } & \multirow[b]{2}{*}{$\mathrm{p}$ Value } \\
\hline & $\begin{array}{c}\text { w/o CSF } \\
\text { Leak }(n= \\
13,659)\end{array}$ & $\begin{array}{c}\text { w/ CSF } \\
\text { Leak }(n= \\
202)\end{array}$ & \\
\hline Age in yrs, mean \pm SD & $8.7 \pm 6.2$ & $10.4 \pm 5.5$ & $<0.0001$ \\
\hline Female & $4686(34.3)$ & $61(30.1)$ & 0.1331 \\
\hline \multicolumn{4}{|l|}{ Type of CSF leak } \\
\hline Otorrhea & NA & $118(58.4)$ & NA \\
\hline Rhinorrhea & NA & $84(41.6)$ & NA \\
\hline Vascular injury & $5565(40.7)$ & $123(60.9)$ & $<0.0001$ \\
\hline Non-CSF otorrhea or rhinorrhea & $242(1.8)$ & $22(10.9)$ & $<0.0001$ \\
\hline Neurosurgical procedure & $1313(9.6)$ & $50(24.8)$ & $<0.0001$ \\
\hline \multicolumn{4}{|l|}{ Skull fracture type } \\
\hline Base & $7162(52.4)$ & $183(90.6)$ & $<0.0001$ \\
\hline Open & $401(2.9)$ & $16(7.9)$ & $<0.0001$ \\
\hline No cerebral injury & $192(1.4)$ & $8(4)$ & 0.0033 \\
\hline Hemorrhage & $164(1.2)$ & $6(3)$ & 0.0277 \\
\hline Laceration & $84(0.6)$ & $5(2.5)$ & 0.0013 \\
\hline Closed & $6968(51)$ & $176(87.1)$ & $<0.0001$ \\
\hline No cerebral injury & $5280(38.7)$ & $143(70.8)$ & $<0.0001$ \\
\hline Hemorrhage & 3020 (22.1) & $87(43.0)$ & $<0.0001$ \\
\hline Laceration & $635(4.6)$ & $21(10.4)$ & 0.0002 \\
\hline Vault & $5696(41.7)$ & $76(37.6)$ & 0.1452 \\
\hline Open & $499(3.7)$ & $13(6.4)$ & 0.0471 \\
\hline No cerebral injury & $266(1.9)$ & $5(2.5)$ & 0.6306 \\
\hline Hemorrhage & $210(1.5)$ & $5(2.5)$ & 0.3112 \\
\hline Laceration & $109(0.8)$ & $7(3.5)$ & $<0.0001$ \\
\hline Closed & $5469(40)$ & 67 (33.1) & 0.0246 \\
\hline No cerebral injury & 3834 (28.1) & $37(18.3)$ & 0.0011 \\
\hline Hemorrhage & 2496 (18.3) & $30(14.9)$ & 0.1603 \\
\hline Laceration & $459(3.4)$ & $9(4.5)$ & 0.4365 \\
\hline Facial fracture & $4906(35.9)$ & $78(38.6)$ & 0.6353 \\
\hline Multiple fractures & $854(6.3)$ & $22(10.9)$ & 0.0109 \\
\hline
\end{tabular}

$\mathrm{NA}=$ not applicable.

Values are presented as the number $(\%)$ of patients unless otherwise indicated. Boldface type indicates statistical significance.

of skull base fractures in both groups $(96.2 \%$ and $97.3 \%$, respectively). They accounted for $87.1 \%(n=176)$ of the fractures in the CSF leak population and $51 \%(\mathrm{n}=6968)$ in the non-CSF leak group ( $\mathrm{p}<0.0001)$. Closed skull base fractures with cerebral hemorrhage and laceration occurred in $43.0 \%(\mathrm{n}=87)$ and $10.4 \%(\mathrm{n}=21)$, respectively, of CSF leak patients, compared with $22.1 \%(n=3020)$ and $4.7 \%(n=635)$ of the non-CSF leak cohort $(p<0.0001$ for hemorrhage; $p=0.0002$ for laceration). A lack of cerebral injury was more frequently seen than cerebral hemorrhage or laceration across both populations with closed skull base fractures, though it represented a larger share in the population with CSF leaks $(n=143[70.8 \%]$ vs 5280 [38.7\%], $\mathrm{p}<0.0001)$. Open vault skull fractures represented $6.4 \%(n=13)$ of the fractures in the CSF leak popula- tion and 3.7\% $(\mathrm{n}=499)$ in the non-CSF leak population $(\mathrm{p}=0.0471)$. Closed vault fractures were seen in $33.1 \%$ ( $\mathrm{n}$ $=67)$ of the CSF leak patients and in 40.1\% $(n=5469)$ of the non-CSF leak patients $(\mathrm{p}=0.0246)$. Multiple fractures were present in $10.9 \%(n=22)$ of the CSF leak population and $6.3 \%(\mathrm{n}=854)$ of the non-CSF leak population $(\mathrm{p}=$ 0.0109).

The modes and rates of neurosurgical intervention were quantified in the CSF leak and non-CSF leak fracture cohorts (Table 2). Of the 202 patients with a CSF leak, 6 (3.0\%) underwent decompressive craniectomies compared with $67(0.5 \%)$ in the general cohort $(\mathrm{p}<0.0001$; OR 6.0; 95\% CI 2.6-14.1). Sixteen patients (7.9\%) with a CSF leak received craniotomies compared with 616 patients $(4.5 \%)$ in the non-CSF leak population $(p=0.0278)$. Differences in external ventricular drain (EVD) $(n=8$ [4.0\%] vs 129 [0.9\%], $\mathrm{p}<0.0001)$ and lumbar drain $(\mathrm{n}=27$ [13.3\%] vs 19 [0.1\%], $\mathrm{p}<0.0001$ ) placement were also noted between patients with CSF leak and those without. Rates of skull fracture fragment elevation were not statistically different between groups. Overall, patients with a CSF leak were more likely to receive craniotomies (OR 1.7; 95\% CI 1.03.0), EVDs (OR 4.2; 95\% CI 2.0-8.7), and lumbar drains (OR 107.5; 95\% CI 58.7-196.8) than patients without CSF leaks.

Patients with CSF leaks experienced worse 90-day outcomes than patients without CSF leaks (Table 3). However, there was no significant difference in mortality between groups $(\mathrm{n}=2[1.0 \%]$ vs $200[1.5 \%], \mathrm{p}=0.5507)$. Compared with the non-CSF leak population, patients with a CSF leak had a longer average LOS (9.6 days vs 3.7 days, $p<$ $0.0001)$ and higher rates of neurological deficits $(5.0 \%$ vs $0.7 \%, \mathrm{p}<0.0001)$, meningitis ( $5.5 \%$ vs $0.3 \%, \mathrm{p}<0.0001)$, nonroutine discharges $(6.9 \%$ vs $2.5 \%, \mathrm{p}<0.0001)$, and readmission $(24.7 \%$ vs $8.5 \%, \mathrm{p}<0.0001)$. Patients with a CSF leak were found to be at a higher risk for neurological deficits (OR 7.0; 95\% CI 3.6-13.6), meningitis (OR 22.4; 95\% CI 11.2-44.9), nonroutine discharge (OR 2.9; $95 \%$ CI 1.7-5.0), and readmission at 90 days (OR 3.4; $95 \%$ CI 2.5-4.7).

Costs incurred at the index hospitalization and at 90 days were quantified (Table 3). Costs and payments were significantly increased for patients with a CSF leak. At the initial hospitalization, average physician payments were greater for the care of patients with a CSF leak (\$2639) than for non-CSF leak patients $(\$ 1599)(\mathrm{p}<0.0001)$. Hospital payments $(\$ 59,128$ vs $\$ 24,092, \mathrm{p}<0.0001)$ and total payments $(\$ 65,833$ vs $\$ 28,426, \mathrm{p}<0.0001)$ were similarly increased. Total costs at 90 days for CSF leak patients averaged $\$ 81,206$ compared with $\$ 32,831$ for patients without CSF leaks ( $\mathrm{p}<0.0001)$.

Readmission events in CSF leak patients were studied in detail (Table 4). Of the 50 patients with CSF leak who were readmitted, 18 (36.0\%) suffered complications from a skull base fracture and $10(20.0 \%)$ were rehabilitating from a surgical procedure. Other causes of readmission were complications from CSF rhinorrhea $(n=8 ; 16.0 \%)$, acquired head deformities $(\mathrm{n}=5 ; 10.0 \%)$, skull vault fractures $(n=5 ; 10.0 \%)$, and CSF otorrhea $(n=4 ; 8.0 \%)$.

The rates of neurosurgical intervention in patients with CSF leaks were further stratified by fracture location (Ta- 


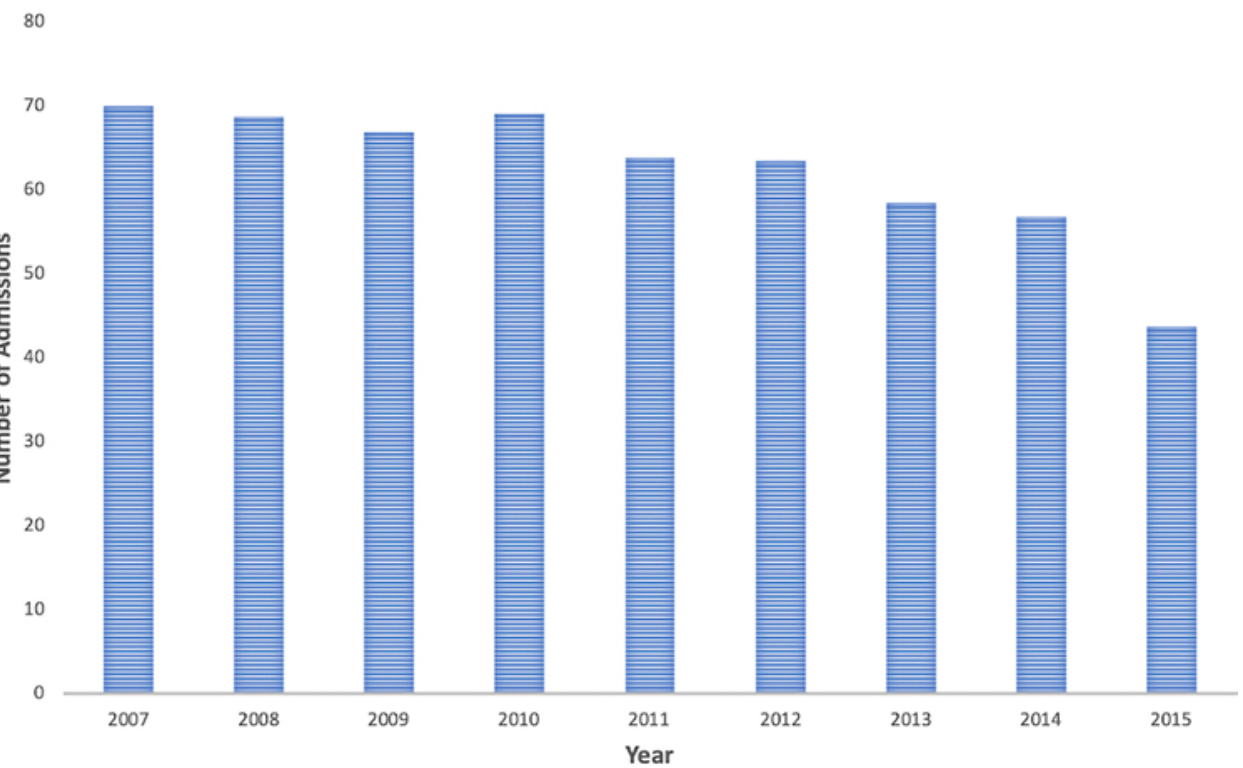

FIG. 1. Skull fracture admissions per 100,000.

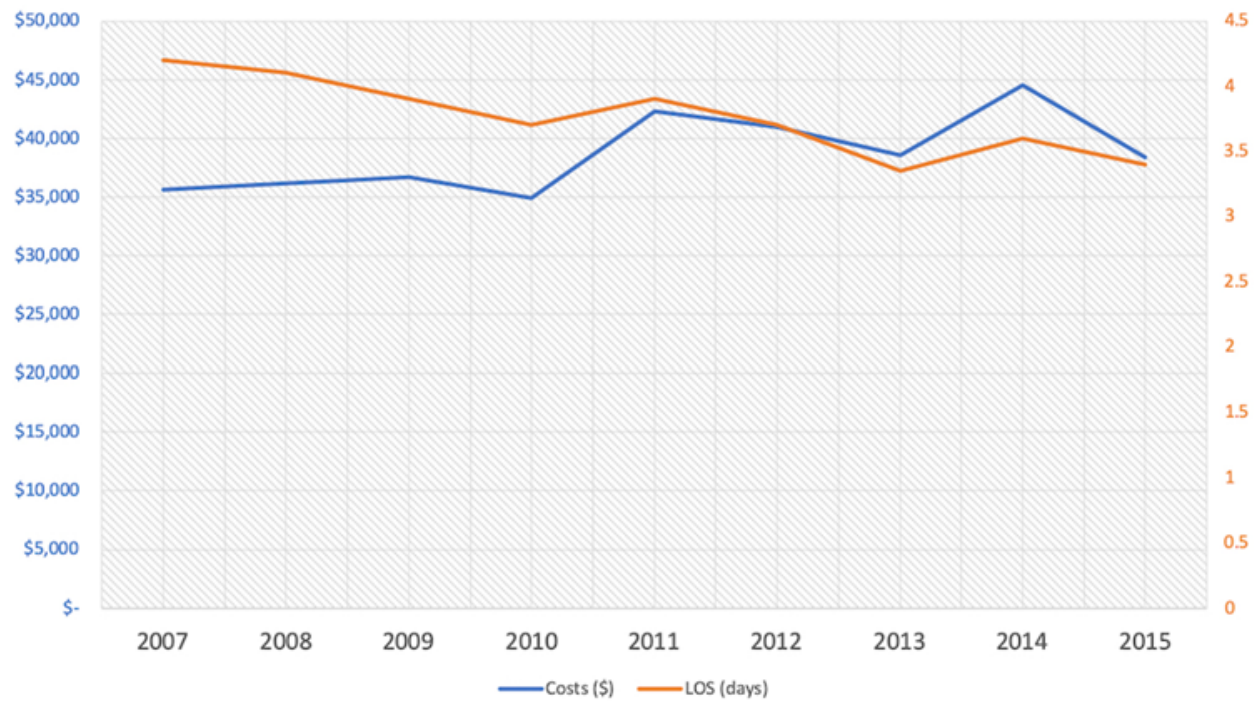

FIG. 2. Impact on the healthcare system over time.

TABLE 2. Surgical procedures

\begin{tabular}{|c|c|c|c|c|}
\hline \multirow[b]{2}{*}{ Variable } & \multicolumn{2}{|c|}{ No. of Patients (\%) } & \multirow[b]{2}{*}{ OR $(95 \% \mathrm{Cl})$} & \multirow[b]{2}{*}{ p Value } \\
\hline & $\begin{array}{l}\text { Skull Fracture w/o CSF Leak } \\
\qquad(n=13,659)\end{array}$ & $\begin{array}{l}\text { Skull Fracture w/ CSF Leak } \\
\qquad(\mathrm{n}=202)\end{array}$ & & \\
\hline Craniectomy & $67(0.5)$ & $6(3.0)$ & $6.0(2.6-14.1)$ & $<0.0001$ \\
\hline Craniotomy & $616(4.5)$ & $16(7.9)$ & $1.7(1.0-3.0)$ & 0.0278 \\
\hline Skull fracture fragments elevated & $659(4.8)$ & $14(6.9)$ & $1.5(0.8-2.5)$ & 0.1991 \\
\hline Lumbar drain placed & $19(0.1)$ & $27(13.4)$ & $107.5(58.7-196.8)$ & $<0.0001$ \\
\hline EVD placed & $129(0.9)$ & $8(4.0)$ & $4.2(2.0-8.7)$ & $<0.0001$ \\
\hline
\end{tabular}

Boldface type indicates statistical significance. 
TABLE 3. Outcomes

\begin{tabular}{|c|c|c|c|c|}
\hline Variable & $\begin{array}{l}\text { Skull Fracture w/o CSF Leak } \\
\qquad(n=13,659)\end{array}$ & $\begin{array}{l}\text { Skull Fracture w/ CSF Leak } \\
\qquad(n=202)\end{array}$ & OR $(95 \% \mathrm{Cl})$ & $p$ Value \\
\hline \multicolumn{5}{|l|}{ 90-day outcomes, no. (\%) } \\
\hline LOS & $3.7 \pm 7.5$ & $9.6 \pm 15.3$ & NA & $<0.0001$ \\
\hline Neurological deficits & $98(0.7)$ & $10(5.0)$ & $7.0(3.6-13.6)$ & $<0.0001$ \\
\hline Meningitis & $34(0.2)$ & $11(5.4)$ & $22.4(11.2-44.9)$ & $<0.0001$ \\
\hline Nonroutine discharge & $335(2.5)$ & $14(6.9)$ & $2.9(1.7-5.0)$ & $<0.0001$ \\
\hline Readmissions & $1158(8.5)$ & $50(24.8)$ & $3.4(2.5-4.7)$ & $<0.0001$ \\
\hline Mortality & $200(1.5)$ & $2(1.0)$ & $0.65(0.2-2.7)$ & 0.5507 \\
\hline \multicolumn{5}{|l|}{ Cost outcomes } \\
\hline \multicolumn{5}{|l|}{ Index hospitalization } \\
\hline Physician payments & $\$ 1,599$ & $\$ 2,639$ & NA & $<0.0001$ \\
\hline Hospital payments & $\$ 24,092$ & $\$ 59,128$ & NA & $<0.0001$ \\
\hline Total payments & $\$ 28,426$ & $\$ 65,833$ & NA & $<0.0001$ \\
\hline \multicolumn{5}{|l|}{ 90-day costs } \\
\hline TBI-related costs & $\$ 15,870$ & $\$ 30,891$ & NA & $<0.0001$ \\
\hline Total costs & $\$ 32,831$ & $\$ 81,206$ & NA & $<0.0001$ \\
\hline
\end{tabular}

$\mathrm{TBI}=$ traumatic brain injury.

Boldface type indicates statistical significance.

ble 5). Of the 176 patients with closed skull base fractures and CSF leaks, 42 underwent a neurosurgical operation (OR 0.4; 95\% CI $0.2-1.0 ; \mathrm{p}<0.0357$ ). Of the 13 patients with open vault fractures, 9 underwent a neurosurgical operation (OR 7.2; 95\% CI 2.1-24.6; $\mathrm{p}<0.0003$ ).

A logistic regression analysis was used to analyze covariates that could be predictive of meningitis risk (Table 6 ). Of the 6 covariates used in the regression, only neurosurgical intervention (OR 5.5; 95\% CI 2.9-10.3; p < $0.0001)$ and the presence of CSF rhinorrhea (OR 26.5; 95\% CI 10.4-59.8; $\mathrm{p}<0.0001$ ) or CSF otorrhea (OR 7.1; $95 \%$ CI 2.2-19.0; $p<0.004)$ were statistically significant. Other factors, including vault or base fractures, non-CSF otorrhea or rhinorrhea, and sex, were not significant.

\section{Discussion}

Skull fractures occur in 10\%-30\% of pediatric head trauma injuries ${ }^{14,18}$ and represent a leading cause of mor-

TABLE 4. Reasons for readmission following the development of CSF leaks

\begin{tabular}{lcc}
\hline \multicolumn{1}{c}{ Variable } & $\begin{array}{c}\text { No. of Patients } \\
(\mathrm{n}=50)\end{array}$ & $\begin{array}{c}\% \text { of } \\
\text { Patients }\end{array}$ \\
\hline Skull base fracture & 18 & $36.0 \%$ \\
\hline Rehabilitation from surgical procedure & 10 & $20.0 \%$ \\
\hline CSF rhinorrhea & 8 & $16.0 \%$ \\
\hline Acquired deformity of the head & 5 & $10.0 \%$ \\
\hline Skull vault fracture & 5 & $10.0 \%$ \\
\hline CSF otorrhea & 4 & $8.0 \%$ \\
\hline
\end{tabular}

bidity. In this study, we used the MarketScan database to assemble, to the best of our knowledge, the largest cohort of pediatric skull fracture patients with CSF leaks in the literature. We found that $1.46 \%$ of pediatric skull fracture patients had a CSF leak, which is lower than previously reported in the pediatric $(2.3 \%)$ and adult $(10 \%-30 \%)$ populations. Our reported incidence of CSF leak (2.49\%) among skull base fractures was similar to the rate (2.33\%) reported by McCutcheon et al., ${ }^{16}$ though substantially lower than that observed by Leibu et al. ${ }^{13}$ (28\%). While rates of neurological deficits, meningitis, and nonroutine discharge were low in both the CSF leak and non-CSF leak groups, we demonstrated that a CSF leak significantly increased the risk for these adverse outcomes. Patients with CSF leaks were 7 times more likely to have a neurological deficit and 22 times more likely to develop

TABLE 5. Neurosurgical intervention in CSF leak patients stratified by skull fracture type

\begin{tabular}{ccrll}
\hline & \multicolumn{2}{c}{ No. of Patients (\%) } & & \\
\cline { 2 - 4 } Variable & $\begin{array}{c}\text { No Surgery } \\
(\mathrm{n}=152)\end{array}$ & $\begin{array}{c}\text { Surgery } \\
(\mathrm{n}=50)\end{array}$ & OR $(95 \% \mathrm{Cl})$ & $\mathrm{p}$ Value \\
\hline Base & $137(90.1)$ & $46(92.0)$ & $0.6(0.2-1.4)$ & 0.1973 \\
\hline Open & $11(7.2)$ & $5(10.0)$ & $1.3(0.4-3.9)$ & 0.6591 \\
\hline Closed & $134(88.2)$ & $42(84.0)$ & $0.4(0.2-1.0)$ & $\mathbf{0 . 0 3 5 7}$ \\
\hline Vault & $48(31.6)$ & $28(56.0)$ & $2.2(1.2-4.2)$ & $\mathbf{0 . 0 1 0 8}$ \\
\hline Open & $4(2.6)$ & $9(18.0)$ & $7.2(2.1-24.6)$ & $\mathbf{0 . 0 0 0 3}$ \\
\hline Closed & $46(30.3)$ & $21(42.0)$ & $1.4(0.7-2.7)$ & 0.2821 \\
\hline
\end{tabular}

Boldface type indicates statistical significance. 
TABLE 6. Logistic regression analysis to identify predictors of meningitis

\begin{tabular}{lrcc}
\hline \multicolumn{1}{c}{ Variable } & OR & $95 \% \mathrm{Cl}$ & $\mathrm{p} \mathrm{Value}$ \\
\hline Neurosurgical intervention & 5.5 & $2.9-10.3$ & $<0.0001$ \\
\hline CSF leak & 14.1 & $6.6-29.0$ & $<0.0001$ \\
\hline$\quad$ Rhinorrhea & 26.5 & $10.4-59.8$ & $<0.0001$ \\
\hline Otorrhea & 7.1 & $2.2-19.0$ & $\mathbf{0 . 0 0 4}$ \\
\hline Non-CSF leak otorrhea/rhinorrhea & 0.5 & $0.1-2.9$ & 0.5671 \\
\hline Sex (female vs male) & 1.1 & $0.6-2.1$ & 0.6671 \\
\hline Vascular injury & 1.7 & $0.9-3.0$ & 0.1061 \\
\hline Vault fracture & 0.8 & $0.4-1.3$ & 0.2805 \\
\hline Base fracture & 1.5 & $0.8-3.1$ & 0.2232 \\
\hline
\end{tabular}

Boldface type indicates statistical significance.

meningitis in the first 90 days following the injury than patients without a CSF leak. The presence of rhinorrhea was much more predictive of future meningitis infection than otorrhea (OR 26.5 vs 7.1, respectively). Additionally, we found that closed skull base and open vault fractures were associated with high rates of CSF leak. In particular, skull base fractures with cerebral hemorrhage and laceration were strongly associated with CSF leak.

Patients with CSF leaks were also far more likely to require a neurosurgical intervention than patients without a leak (24.8\% vs $9.6 \%)$, especially decompressive craniectomies (OR 6.0), EVDs (OR 4.2), and lumbar drains (OR 107.5). This discrepancy is similar to those previously reported ${ }^{7,20}$ and likely highlights the increased risks associated with CSF leak, including encephalitis and growing pneumocephalus. ${ }^{1,13}$ The nature of the data does not allow us to draw conclusions about the causality of the found associations, however, and the high rate of CSF leaks in the identified populations at risk might also be a result rather than a cause of treatment. Patients who ended up developing a CSF leak may have suffered from more severe injuries, requiring decompressive craniectomies to manage brain edema or EVD placement to relieve intracranial hypertension from swelling or associated posttraumatic hydrocephalus. Those are conditions with an intrinsic risk for CSF leaks. In support of this hypothesis, we observed a significantly higher rate of vascular injury in the CSF leak population than in the general cohort $(60.9 \%$ vs $40.7 \%$, $\mathrm{p}<0.0001)$. Still, the vast majority of patients with CSF leaks $(75.2 \%)$ did not receive a neurosurgical procedure, echoing past studies that reported high rates of spontaneous CSF leak resolution or resolution with drainage and acetazolamide treatment. ${ }^{13}$ When rates of neurosurgical intervention in patients with CSF leaks were stratified by fracture location, it was observed that only $23.9 \%(n=42)$ of patients with closed skull base fractures underwent an operation. This is contrasted with $69.2 \%(n=9)$ of patients with open vault fractures, though the different sample sizes limit definitive comparisons.

The healthcare costs associated with pediatric skull fracture patients with CSF leaks have not been well documented in the literature. ${ }^{6,21}$ Traumatic CSF leaks are as- sociated with greater hospital and physician expenditures, both at the index hospitalization and at 90 days. However, since average LOSs were longer in the CSF leak cohort than in the non-CSF leak cohort, it is possible that the difference in costs is largely attributable to prolonged admission, ${ }^{6,21}$ especially in the intensive care unit. The increased rates of neurosurgical procedures for patients with CSF leaks are also likely contributors to the elevated costs associated with their care. Finally, patients with CSF leaks who develop meningitis or neurological deficits require significantly more resources, thus driving up average costs for the entire cohort. Further cost analyses stratified by comorbidities and LOS are needed to more precisely characterize the cost discrepancies between pediatric skull fracture patients with CSF leaks and those without CSF leaks.

Between 2007 and 2015, skull fracture admissions declined by more than $40 \%$ and the average LOS decreased by $19 \%$, yet costs still increased by roughly $20 \%$. The inverse relationship between LOS and cost is concerning and without obvious explanation. While a majority of pediatric patients with skull fractures are aggressively managed and admitted at high rates, ${ }^{15}$ there is little extant data on longitudinal treatment trends. Notably, the majority of the cost increase occurred after 2010, which coincided with the passage and implementation of major healthcare reform. Further investigation is needed to determine how much of the cost increase is due to the general rise in healthcare prices versus more specific skull fracture-related treatment paradigms.

Over the past decade, numerous reports have indicated that a majority of CSF leaks resolve spontaneously and do not require surgical intervention. While CSF leaks are rare after pediatric skull fractures, they are associated with significant morbidity, including meningitis and neurological deficits. Close clinical surveillance is required for this population, particularly those with multiple fractures or closed basilar skull fractures. Given the increased risk of adverse outcomes in patients with CSF leaks, we suggest further investigation to determine whether or not more aggressive treatment-including early drainage, decompression, or prophylactic antibiotic treatment-may be warranted.

\section{Limitations}

As with all large database studies, interpretations of this study are limited by the administrative nature of the data. We assumed the accuracy of all diagnosis and procedure codes in the database. The MarketScan database aggregates data on commercially insured patients. Because patients, procedures, and clinical outcomes were queried using ICD-9-CM codes, it is not possible to assess the underlying validity of the collected records. Additionally, potential questions and analyses are constrained by the specificity of the ICD codes. For example, ICD codes do not include depressed or growing skull fractures, specific bones fractured, or antibiotics used, and, therefore, their specific associations with rates of CSF leak and meningitis risk could not be explored. The severity of the disease is also not discernable in MarketScan data. Finally, because the MarketScan database only covers insured patients, this 
study has substantial selection bias against uninsured pediatric patients with skull fractures. Lack of insurance has been previously implicated in longer hospitalizations ${ }^{26}$ and lower readmission rates ${ }^{16}$ for patients with skull fractures. Unfortunately, this could not be assessed in the current study.

\section{Conclusions}

We found that CSF leaks occurred in $1.46 \%$ of pediatric patients with skull fractures, and the leaks were associated with significantly increased rates of neurosurgical intervention and risks of meningitis, hospital readmission, and neurological deficits at 90 days. In particular, patients with CSF rhinorrhea were much more likely to develop meningitis than patients with otorrhea, but vascular injury, sex, and base or vault fractures were not predictive factors. Pediatric patients with skull fractures also experienced a longer average LOS and greater healthcare costs at presentation and at 90 days. Further studies should investigate the risk factors of developing a CSF leak following skull fracture, the role of surgical intervention in its management, and the benefit of prophylactic antibiotics.

\section{References}

1. Adepoju A, Adamo MA: Posttraumatic complications in pediatric skull fracture: dural sinus thrombosis, arterial dissection, and cerebrospinal fluid leakage. J Neurosurg Pediatr 20:598-603, 2017

2. Alexiou GA, Sfakianos G, Prodromou N: Pediatric head trauma. J Emerg Trauma Shock 4:403-408, 2011

3. Arneitz C, Sinzig M, Fasching G: Diagnostic and clinical management of skull fractures in children. J Clin Imaging Sci 6:47, 2016

4. Arrey EN, Kerr ML, Fletcher S, Cox CS Jr, Sandberg DI: Linear nondisplaced skull fractures in children: who should be observed or admitted? J Neurosurg Pediatr 16:703-708, 2015

5. Beckhardt RN, Setzen M, Carras R: Primary spontaneous cerebrospinal fluid rhinorrhea. Otolaryngol Head Neck Surg 104:425-432, 1991

6. Blackwood BP, Bean JF, Sadecki-Lund C, Helenowski IB, Kabre R, Hunter CJ: Observation for isolated traumatic skull fractures in the pediatric population: unnecessary and costly. J Pediatr Surg 51:654-658, 2016

7. Bonfield CM, Naran S, Adetayo OA, Pollack IF, Losee JE: Pediatric skull fractures: the need for surgical intervention, characteristics, complications, and outcomes. J Neurosurg Pediatr 14:205-211, 2014

8. Bressan S, Marchetto L, Lyons TW, Monuteaux MC, Freedman SB, Da Dalt L, et al: A systematic review and metaanalysis of the management and outcomes of isolated skull fractures in children. Ann Emerg Med 71:714-724.e2, 2018

9. Donaldson K, Li X, Sartorelli KH, Weimersheimer P, Durham SR: Management of isolated skull fractures in pediatric patients: a systematic review. Pediatr Emerg Care 35:301308, 2019

10. Erşahin Y, Mutluer S, Mirzai H, Palali I: Pediatric depressed skull fractures: analysis of 530 cases. Childs Nerv Syst 12:323-331, 1996

11. Friedman JA, Ebersold MJ, Quast LM: Persistent posttraumatic cerebrospinal fluid leakage. Neurosurg Focus 9(1):e1, 2000

12. Greenes DS, Schutzman SA: Infants with isolated skull fracture: what are their clinical characteristics, and do they require hospitalization? Ann Emerg Med 30:253-259, 1997

13. Leibu S, Rosenthal G, Shoshan Y, Benifla M: Clinical significance of long-term follow-up of children with posttraumatic skull base fracture. World Neurosurg 103:315-321, 2017

14. Mann KS, Chan KH, Yue CP: Skull fractures in children: their assessment in relation to developmental skull changes and acute intracranial hematomas. Childs Nerv Syst 2:258261, 1986

15. Mannix R, Monuteaux MC, Schutzman SA, Meehan WP III, Nigrovic LE, Neuman MI: Isolated skull fractures: trends in management in US pediatric emergency departments. Ann Emerg Med 62:327-331, 2013

16. McCutcheon BA, Orosco RK, Chang DC, Salazar FR, Talamini MA, Maturo S, et al: Outcomes of isolated basilar skull fracture: readmission, meningitis, and cerebrospinal fluid leak. Otolaryngol Head Neck Surg 149:931-939, 2013

17. Metzger RR, Smith J, Wells M, Eldridge L, Holsti M, Scaife $\mathrm{ER}$, et al: Impact of newly adopted guidelines for management of children with isolated skull fracture. J Pediatr Surg 49:1856-1860, 2014

18. Nelson EL, Melton LJ III, Annegers JF, Laws ER, Offord KP: Incidence of skull fractures in Olmsted County, Minnesota. Neurosurgery 15:318-324, 1984

19. Olshaker JS, Whye DW Jr: Head trauma. Emerg Med Clin North Am 11:165-186, 1993

20. Perheentupa U, Kinnunen I, Grénman R, Aitasalo K, Mäkitie AA: Management and outcome of pediatric skull base fractures. Int J Pediatr Otorhinolaryngol 74:1245-1250, 2010

21. Plackett TP, Asturias S, Tadlock M, Wright F, Ton-That H, Demetriades D, et al: Re-evaluating the need for hospital admission and observation of pediatric traumatic brain injury after a normal head CT. J Pediatr Surg 50:1758-1761, 2015

22. Powell EC, Atabaki SM, Wootton-Gorges S, Wisner D, Mahajan P, Glass T, et al: Isolated linear skull fractures in children with blunt head trauma. Pediatrics 135:e851-e857, 2015

23. Rollins MD, Barnhart DC, Greenberg RA, Scaife ER, Holsti M, Meyers RL, et al: Neurologically intact children with an isolated skull fracture may be safely discharged after brief observation. J Pediatr Surg 46:1342-1346, 2011

24. Sivanandapanicker J, Nagar M, Kutty R, Sunilkumar BS Peethambaran A, Rajmohan BP, et al: Analysis and clinical importance of skull base fractures in adult patients with traumatic brain injury. J Neurosci Rural Pract 9:370-375, 2018

25. Tunik MG, Powell EC, Mahajan P, Schunk JE, Jacobs E, Miskin M, et al: Clinical presentations and outcomes of children with basilar skull fractures after blunt head trauma. Ann Emerg Med 68:431-440.e1, 2016

26. Williams DC, Selassie AW, Russell WS, Borg KT, Basco WT Jr: Risk factors for admission and prolonged length of stay in pediatric isolated skull fractures. Pediatr Emerg Care 33:e146-e151, 2017

27. Yellinek S, Cohen A, Merkin V, Shelef I, Benifla M: Clinical significance of skull base fracture in patients after traumatic brain injury. J Clin Neurosci 25:111-115, 2016

28. Yilmazlar S, Arslan E, Kocaeli H, Dogan S, Aksoy K, Korfali E, et al: Cerebrospinal fluid leakage complicating skull base fractures: analysis of 81 cases. Neurosurg Rev 29:6471, 2006

29. Ziu M, Savage JG, Jimenez DF: Diagnosis and treatment of cerebrospinal fluid rhinorrhea following accidental traumatic anterior skull base fractures. Neurosurg Focus 32(6):E3, 2012

\section{Disclosures}

Dr. Veeravagu reports being a consultant for NuVasive, Medtronic, and Surgical Theater. 


\section{Author Contributions}

Conception and design: Veeravagu, Varshneya, Rodrigues,

Medress. Acquisition of data: Varshneya, Rodrigues, Medress.

Analysis and interpretation of data: Varshneya, Rodrigues,

Medress. Drafting the article: Varshneya, Rodrigues, Stienen,

Grant. Critically revising the article: Veeravagu, Varshneya,

Rodrigues, Stienen, Grant. Reviewed submitted version of manuscript: Varshneya, Rodrigues, Medress, Stienen, Grant, Ratliff. Statistical analysis: Veeravagu, Varshneya. Administrative/technical/material support: Veeravagu, Rodrigues, Medress, Grant, Ratliff. Study supervision: Veeravagu, Medress, Stienen, Grant, Ratliff.

\section{Correspondence}

Anand Veeravagu: Stanford University School of Medicine, Stanford,CA. anandv2@stanford.edu. 